\title{
Preventive detention exhumed - and enhanced
}

\author{
Derek Chiswick
}

In 1997 there were 57000 notifiable crimes of serious or sexual violence recorded by police in England and Wales (Home Office, 1998) - more than 1000 per week or approximately one every 10 minutes. On 15 February 1999 the Home Secretary, Jack Straw, announced new measures "better to protect the public from dangerous people in our society" (House of Commons, 1999). He said the measures were to target "those who are capable of committing acts of a serious sexual or violent nature". Of the 57000 potential targets, Mr Straw believes 1800 men are already detained in prisons and special hospitals; he intends to identify a further $\mathbf{5 0 0}$ or so men currently at liberty and lock them away indefinitely, in advance of their offending. His intention in respect of the other 54700 violent or sexual offenders, responsible for $99 \%$ of serious violence, is not stated. Mr Straw believes that the 500 men in the community (and the 1800 in custody) share a common psychiatric condition and that this is what makes them dangerous. His policy for identifying the men, and what he intends to do with them and similar people, is contained in the recently published consultation paper on dangerous people with severe personality disorder (Home Office \& Department of Health, 1999).

The paper is styled in the customary language of modern government. There is to be "a coherent strategy", a "framework for the future" and projects that will involve a wide range of "stakeholders". Indeed "collaboration with key stakeholders" is said to be a priority. Psychiatrists will be not only holders of stakes but also keys, for the presence of a special type of mental condition is a prerequisite for indefinite detention: without this condition, Mr Straw's policy collapses like a house of cards. Unsoundness of mind is the sine qua non for indefinite detention, necessary to satisfy Article 5.1(e) of the European Convention on Human Rights (ECHR). The government has identified a psychiatric condition it believes will comply with the unsoundness of mind criterion of the ECHR. The people it seeks to detain are the dangerous severely personality disordered'; the government's confidence is such that the condition is reifled with the initials, 'DSPD'. The definition is of the circular type, familiar in mental health legislation - the behaviour is the disorder, and the disorder is the behaviour.

The government is confident that the diagnosis of DSPD can be made but we are not told which population will undergo diagnostic testing. Perhaps it is the annual 57000 violent offenders or possibly the $\mathbf{2 0}$ million adult men in England and Wales, of whom an unquantifiable number is "capable of committing acts of a serious sexual or violent nature". Specificity of the test will need to be extremely accurate for the stakes are high. A marginal diagnostic error of $1 \%$ applied to the adult male population will result in 200000 unfortunate men being wrongly detained for life.

The inexorable rise in violent crime, mirrored in all Western countries, in the last 50 years deserves government attention and action but few will regard the invention of a new psychiatric disorder as an appropriate starting point. If personality disorder is the overriding concern. there are alternative ways in which courts and psychiatrists can make a reasonable contribution to its assessment and long-term management. The Ashworth Inquiry Report (Fallon et al, 1999) made sensible suggestions including a new reviewable sentence for certain offenders. Elsewhere, Maden (1999, this issue) explores the ways in which psychiatrists could more properly offer treatment to those offenders in prison or in the community who wish to be helped.

Legal powers to impose longer, or indefinite, sentences and mandatory supervision after release for serious offenders currently exist in England but have had a limited take-up. Her Majesty's judges currently impose a life sentence in only $2 \%$ of cases where it is a possible sentencing option (Home Office \& Department of Health, 1999). In most jurisdictions the notion of longer than usual sentences is tied to a perceived high risk of re-offending, rather than to a mental disorder. There are understandable arguments for this position and indeed $\mathbf{M r}$ Straw's consultation paper refers to some of them. However, in seeking indefinitely to incarcerate some individuals before they offend, on 
the basis of a spurious mental condition, the English government acts alone.

The paper looks forward "in time to a reduction in the level of the most serious offending by people with severe personality disorder". Indeed, performance will be measured in terms of an anticipated reduction of "nearly 200 serious crimes a year". This reduction of less than $0.4 \%$ in the violent crime figures will defy both measurement and attribution. It will be 'achieved' (the paper does not tell us how the day of achievement is to be recognised) at a cost of massive prison expansion, and by the incarceration of potentially thousands of men on the basis of what they might do in the future.

We are assured the 'framework' is intended to support research and training activity. However, the government's application of research in this field sends shivers down the spine. For example, the findings of the respected Office for National Statistics (ONS) study (Singleton et al, 1998) are cited in support of the estimate of 1422 men with DSPD in prison. The ONS study showed that $49 \%$ of sentenced men had an antisocial personality disorder. The consultation paper mentions an unreferenced "meta-analysis of about 60 world-wide studies" (none of them referenced) and, by a smoke-and-mirrors extrapolation. arrives at the figure of 1422 prisoners with DSPD who need locking up for life. Closer scrutiny of the ONS study shows that antisocial personality disorder was in fact more likely to be associated with crimes of burglary, robbery and theft than it was with violent or sexual offending.

The folly of equating high risk with a dubious psychiatric diagnosis to the exclusion of other relevant factors cannot be over-emphasised. It arises because Mr Straw's policy is not based on clinical or academic knowledge, but on caricature. It is a populist measure drawn up in response to alarmist fears, some of them generated by government ministers. The proposals serve to demonise mental disorder and to fuel the stigmatisation of the mentally ill. Notwithstanding the presentational spin, this consultation paper is about the exhumation and enhancement of preventive detention, a measure that suffered a slow death before burial in 1967. Resuscitation of this particular corpse depends entirely on the connivance of psychiatrists. Now the profession must decide where it stands.

\section{References}

FALLON, P., BLuglass, R., EDWARDS, B., et al (1999) Report of the Committee of Inquiry into the Personality Disorder Unit, Ashworth Special Hospital. Volume 1. Cm419411. London: The Stationery Office.

HOME OFFICE (1998) Criminal Statistics England and Wales 1997. Cm 4162. London: The Stationery Office.

HOME OfFCE \& DEPARTMENT OF HEALTH (1999) Managing Dangerous People with Severe Personality Disorder. London: Home Office \& Department of Health.

House OF Commons (1999) Hansard Debates for 15 February 1999. Columns 610-613. London: The Stationery Office.

MADEN, T. (1999) Treating offenders with personality disorder. Psychiatric Bulletin, 23, 707-710.

Singleton, N., MEltzer, H. \& GATWARD, R. (1998) Psychiatric Morbidity Among Prisoners in England and Wales. London: The Stationery Office.

Derek Chiswick, Consultant Forensic Psychiatrist, Royal Edinburgh Hospital, Morningside Terrace, Edinburgh EHIO 5HF 